\title{
Ritualismo e nacionalização da escola primária em Santa Catarina (anos 1940)
}

\author{
Ademir Valdir dos Santos \\ Universidade Federal de Santa Catarina
}

\section{Resumo}

Objetiva discutir o ritualismo como aspecto da organização política e pedagógica de escolas primárias de Santa Catarina na década de 1940. Analisa rituais entendidos como parte do coletivo de práticas e políticas que almejaram forjar nas crianças atitudes cívico-patrióticas, com a utilização da escola a serviço da nacionalização. É uma pesquisa documental embasada na análise de atas e programas de rituais produzidos em escolas rurais de região de imigração alemã, efetuada através da análise de conteúdo, com o uso de codificação. Os resultados mostram que os rituais eram cerimônias e festas que celebravam datas e personagens históricos, cuja natureza nacionalista é revelada por hinos, canto, poesia, desfile cívico, mostra de Educação Física, ginástica, teatro, jogos, brincadeiras, distribuição de prêmios e doces. Indicam também que pretendiam a formação infantil conforme o pensamento republicano. E almejavam inculcar devoção à pátria, gerando, na escola, um ambiente de ritualismo para nacionalizar a infância.

Palavras-chave: História da educação brasileira. Escola primária. Festa escolar. Nacionalismo.

\section{Ritualism and nationalization of the elementary school in Santa Catarina (1940s)}

\section{Abstract}

It aims to discuss ritualism as an aspect of the political and pedagogical organization of elementary schools in Santa Catarina in the 1940s. It analyzes rituals understood as part of a collective of practices and policies that aimed to forge in children civic-patriotic attitudes, with the use of the school at the service of nationalization. It is a documentary research based on the analysis of minutes and ritual programs produced in rural schools in a German immigration region, carried out through content analysis, using coding. The results show that rituals were ceremonies and celebrations celebrating historical dates and characters, whose nationalistic nature is revealed by hymns, singing, poetry, civic parade, Physical Education show, gymnastics, theater, games, plays, distribution of prizes and sweets. Results also indicate that they intended child formation according to republican thinking. And they wanted to inculcate devotion to homeland, generating, in the school, an atmosphere of ritualism to nationalize childhood.

Keywords: History of Brazilian education. Elementary school. School party. Nationalism. 


\section{Ritualismo y nacionalización de la escuela primaria en Santa Catarina (años 1940)}

\section{Resumen}

El objetivo es discutir el ritualismo como aspecto de la organización política y pedagógica de escuelas primarias de Santa Catarina en la década de 1940. Analiza rituales entendidos como parte del colectivo de prácticas y políticas que pretendían forjar en los niños actitudes cívico-patrióticas, con la utilización de la escuela al servicio de la nacionalización. Es una investigación documental basada en el análisis de programas de actas y rituales producidos en escuelas rurales de región de inmigración alemana, efectuada a través del análisis de contenido, con el uso de codificación. Los resultados muestran que los rituales eran ceremonias y fiestas que celebraban fechas y personajes históricos, cuya naturaleza nacionalista es revelada por himnos, canto, poesía, desfile cívico, muestra de Educación Física, gimnasia, teatro, juegos infantiles, distribución de premios y dulces. También indican que esos rituales pretendían la formación infantil según el pensamiento republicano. Y pretendían inculcar devoción a la patria, generando en la escuela un ambiente de ritualismo para nacionalizar la infancia.

Palabras clave: Historia de la educación brasileña. Escuela primaria. Fiestas de la escuela. Nacionalismo.

\section{Introdução}

Constituintes da cultura material e simbólica escolar, os rituais são componentes do fenômeno educativo e expressam aspectos da formação pedagógica, abrangendo o pessoal administrativo, a organização burocrática, os programas, os controles e as provas (CURY, 1987). Com base na admissão de tal conceito, torna-se viável discutir os rituais enquanto mecanismos para disciplinar, como meios práticos de impor novos ritmos, formas e conteúdos para ocupar o tempo, entendidos como necessários e mais adequados aos contextos. Além disso, se concebe que os rituais podem funcionar como ações aliadas de outras transformações da organização educacional requisitadas pelas circunstâncias, conformes ao ideário social que se busca instalar. Argumento ainda no sentido de que por admitir uma conjugação de costumes, regras e práticas, o ritual inclui cerimoniais como as "festas escolares", concordando

[...] que elas compõem fatos sociais, e o seu estudo ganha importância não somente do ponto de vista histórico, mas também 
antropológico, colocando em destaque momentos simbólicos de integralização dos atores do universo escolar em frente à construção de instrumentos que as viabilizem na qualidade de fenômeno cultural (BENCOSTTA, 2010, p. 251 ).

Já o ritualismo deriva da compreensão de que é possível promover a integração e o demasiado apego às formalidades, por meio da utilização de simbologia do campo cultural inserida na repetição sistemática de rituais, de modo a conciliar os sujeitos com o meio e gerar consistência dos ideais sociais apresentados como desejáveis ordenadores da realidade. Em decorrência, admite-se a possibilidade de que as cerimônias e festas escolares possam ter representado momentos de instituição do uso exacerbado do ritual: manifestação presente como protocolo, rotina, culto e costume.

objetivo deste texto é apresentar e discutir o ritualismo como aspecto da organização política e pedagógica de um conjunto de escolas primárias de Santa Catarina na década de 1940. Busca-se caracterizar e analisar rituais escolares entendidos como expressões de parte do coletivo de práticas e políticas que almejaram forjar nas crianças atitudes cívico-patrióticas e discipliná-las para ocupar o tempo, com a utilização da escola primária a serviço de um projeto de nacionalização.

estudo se alicerça na hipótese de que, de modo geral, e atingindo a diversidade institucional então existente, o ritualismo serviu à formação da infância buscando harmonização com aspectos do ideário do período republicano. Isto porque a escola pública primária deveria assimilar novas orientações quanto às suas práticas, segundo a afirmação de um regime político intimamente vinculado à modernização educacional administrativo-pedagógica, que foi incorporando, ao longo do tempo, aspectos do nacionalismo. Em função disto, a investigação dialoga com investigações que mostram que, desde meados do século XX, mas sobretudo nos anos de 1930 e 1940, os quais compreendem um período do governo de Getúlio Vargas, instituições escolares foram utilizadas como ambiente para uma campanha de nacionalização em que os rituais tomaram parte.

Quanto à metodologia, está embasada em pesquisa documental, utilizando como fontes primárias atas e programas que expressam atividades ritualísticas inseridas no currículo de um conjunto composto por dez escolas de ensino primário. A análise de atas e programas é efetuada através do processo 
de codificação, componente da metodologia de análise de conteúdo, atividade em que o investigador organiza e agrupa termos considerados como indicadores, com o propósito de descrição das características do conteúdo, por meio de recortes do texto (BARDIN, 1977). A amostra de instituições é caracterizada na próxima seção, seja para situá-la no panorama mais amplo da educação brasileira, como também devido às particularidades do processo histórico de sua criação e funcionamento em Santa Catarina. Na sequência, são abordados o contexto republicano e os aspectos da ritualidade ali presentes. Como núcleo da escrita, o texto propõe um exame do teor de atas e programas dos rituais, descrevendo e analisando cerimônias e festas realizadas nas escolas, à luz de outras fontes e referenciais. Ao final, são elaboradas considerações que propõem contextualização das finalidades e significados sociais, culturais e políticos do ritualismo nas escolas catarinenses na década de 1940.

\section{A diversidade de instituições escolares em Santa Catarina}

Para que se tenha clareza sobre a natureza das instituições que compõem a amostra, cabe introduzir alguns elementos quanto às suas origens e às transformações por que passaram no decurso histórico. Muitas das escolas que, na década de 1940, estavam ativas e mantinham a denominação de isoladas, existiam desde o período Imperial e estavam espalhadas pelo território catarinense. Mas nem sempre foram assim designadas. É que, no final do século XIX ou nas primeiras décadas da centúria seguinte, boa parte daquelas havia sido fundada por iniciativa de comunidades cuja composição populacional incluía, quando não a, totalidade, um significativo número de imigrantes estrangeiros de diversas etnias que havia se fixado em Santa Catarina, nas chamadas colônias.

Disso, resultaram, entre outros empreendimentos sociais, escolas em que a organização pedagógica e didática foi marcada por referenciais culturais distintos dos brasileiros, como a utilização de idioma estrangeiro e de arranjos curriculares cuja matriz de conhecimento era internacional. Conforme os estudos organizados por Fiori (2003), no sul do Brasil, existia considerável número de instituições cuja denominação inicial trazia consigo o caráter étnico que as marcava culturalmente: escolas alemãs, italianas, polonesas, entre 
outras. Por isso, foram classificadas pelo governo como comunitárias, privadas ou mesmo como estrangeiras no Brasil. Com o passar dos anos e devido às trocas interculturais, mas também em função de modificações nas políticas educacionais, ocorria um abrasileiramento que impactava na identidade institucional. De acordo com Santos (2014), no período entre o final dos oitocentos e os anos 1930, as típicas "escolas alemãs" catarinenses gradativamente se transformaram em "teuto-brasileiras". Porém, isto não resultou em que essas escolas e as comunidades do entorno fossem entendidas como genuinamente brasileiras. Pelo menos até a metade da década de 1940 continuava ocorrendo um processo de nacionalização das escolas situadas nas regiões de imigração alemã, liderado pelos governos federal e estadual:

Calcou-se na prescrição de práticas culturais para a infância e juventude com ascendência estrangeira, imbuídas de valores e atitudes que pretendiam o aprendizado e inculcação não apenas na língua portuguesa, mas de um patriotismo devotado à nação brasileira. O período do Estado Novo (1937-1945), capitaneado por Getúlio Vargas, foi o momento de sua maior exacerbação, embora diversas expressões de nacionalismo viessem sendo gestadas desde a Primeira Guerra Mundial. Alimentadas pela legislação e por órgãos de gestão educacional, campanhas de abrasileiramento foram dirigidas às escolas de imigrantes e tinham o objetivo de orientar a ação pedagógica para uma consequente extinção do germanismo nas comunidades alienígenas (SANTOS, 2015, p. 336).

Especificamente em 1938, leis federais proibiram, definitivamente, a atividade das ainda consideradas escolas estrangeiras (BOMENY, 1999). Mas aquelas que conseguiram manter sua atividade devido atender às mudanças requisitadas, na sua estruturação didático-pedagógica e administrativa, acabaram incorporadas aos sistemas municipais ou estaduais, recebendo novos nomes e classificação.

E coube àquelas escolinhas do meio rural manter a denominação: antes isoladas devido à distribuição na geografia catarinense, ganhavam agora um nome oficial que, de certo modo, preservava alguns aspectos de sua identidade. Isto porque, geralmente, essas escolas estavam situadas em áreas rurais ou suburbanas, funcionavam sob a responsabilidade de um único professor (unidocência) e ofertavam três ou quatro séries agrupadas em uma 
mesma sala de aula (multisseriadas). E embora existam registros de edificações que foram erguidas com a única finalidade de abrigar a instituição, a maioria das escolas isoladas mantinha uma infraestrutura simples, por vezes precária. Era comum que funcionassem em uma casa que servia também como moradia para o docente, ou compartilhando algum lugar pertencente à comunidade religiosa local. Quando chamadas de mistas, atendiam a crianças de ambos os sexos. E como desdobrada ficou conhecida cada uma das frações restantes da cisão efetuada em uma instituição devido a um excedente no número de matrículas, reagrupando os estudantes de modo que pudessem ser atendidos em outro tempo e espaço escolares, em novas classes.

Embora ensinassem a ler, escrever e contar, representando a única possibilidade histórica de instrução elementar para boa parte da população infantil, a partir das primeiras décadas do século XX, as escolas isoladas vinham sendo apontadas como sinônimo de atraso em relação a emergentes propostas educacionais de inspiração republicana que traziam um discurso modernizador, de que foi veículo o denominado grupo escolar: a retórica da formação de um novo sujeito, preparado para auxiliar o desenvolvimento e vir a ser um cidadão a serviço da pátria. Segundo Teive e Dallabrida (201 1, p. 17), a instituição dos grupos escolares se deu a partir de 191 1, com a criação de unidades nas principais cidades catarinenses em meados do século passado: "[...] afinando a modernização do seu ensino primário com o modelo de escola graduada em circulação no mundo ocidental desde a segunda metade do século XIX". Devido às transformações causadas na história da escolarização brasileira, o grupo escolar tem sido objeto de várias pesquisas e de decorrente visibilidade. Porém, cabe lembrar que, em Santa Catarina, foram inaugurados apenas sete grupos escolares, que, descentralizados na geografia estadual e instalados no ambiente urbano das cidades-polo da época, acabaram por atender a uma pequena parcela da população estudantil. Portanto, às centenas de pequenas escolas primárias rurais cabia seguir atuando.

Estabelecidas, portanto, diferenciações quanto ao tipo de instituição focalizado e aos contextos considerados para interpretação, analisa-se, pois, a programação de rituais, descritos em documentos produzidos em escolas primárias rurais situadas em localidades remanescentes do processo de imigração alemã, vistas pelo governo como necessitando ser abrasileiradas. Tal recorte geográfico e tipológico acabava utilizado como motivo para que a 
nacionalização fosse efetivada, vindo a ser as escolas isoladas e assemelhadas o principal alvo das campanhas.

Por isso, este estudo é justificado como um modo de trazer, à tona, elementos do fenômeno educacional pautados pela ampliação do foco sobre a diversidade de instituições que existia. Dito isso, considerada a diferenciação citada e que exige outras perspectivas analíticas, este texto busca acrescentar na historiografia por tratar de rituais em escolas menos visíveis nos estudos em história da educação, mas atuantes na oferta de ensino primário em Santa Catarina num âmbito cronológico de busca pela consolidação do regime republicano.

\section{A criação de um ambiente para o ritualismo}

Numa caracterização da educação escolar no Brasil republicano, são intruzidos, inicialmente, alguns elementos do período que constitui a Primeira República ou República Velha (1 889-1930). Segundo Nagle (1997, p. 268), nessa época, a escola primária era incumbência da administração de cada 202 um dos Estados; por esse motivo, o Governo Federal, tardiamente, veio a se preocupar com a qualidade do ensino, o que teria ocorrido muito mais em função de vir à tona a "[...] situação humilhante revelada pelas estatísticas escolares, referentes à escola primária [...]", propagada na Conferência do Ensino Primário de 1921.

De acordo com a tese de Nagle (1997), a defesa da escola primária foi uma das características do processo de "entusiasmo pela educação", questão de fundo político que preconizou o aumento do número de instituições de modo a que se buscasse ter escola para todos - melhor dizendo, para o povo; outrossim, tal aspecto constituiu um dado típico da ação republicana, envolvendo os Estados numa difusão da escolarização, sendo que, particularmente na região meridional do país, acabou por fundir a luta contra o descaso pela educação primária com as campanhas nacionalistas. Ou seja, há uma relação entre os fenômenos de republicanização e nacionalismo.

Então, para que se tornem mais nítidas as análises a serem feitas, ratificam-se alguns argumentos derivados: "Duas tendências precisam ser ainda mencionadas a respeito da escola primária [...]: a da nacionalização e a da regionalização e ruralização" (NAGLE, 1997, p.272, grifos meus). Como 
indicado, o nacionalismo é evocado devido ao fato de que as instituições que constituem objeto deste estudo foram alvo de campanhas nacionalistas, ao mesmo tempo que a localização de escolas primárias, em áreas rurais, as vincula a outra tendência destacada.

Os propósitos de nacionalização avançaram, notoriamente, na primeira metade do século passado, enfatizando a devoção ao Brasil como a única e verdadeira pátria e, ao mesmo tempo, buscando desconstruir qualquer referência cultural oriunda de outra nação presente no meio social, especialmente durante o governo de Getúlio Vargas (1930-45) e, com mais vigor nacionalista, no período do Estado Novo (1937-1945):

[...] nas regiões catarinenses de imigração alemã, a educação escolar foi utilizada como veículo para a construção de uma identidade nacional alinhada à campanha de nacionalização então em voga. A ação governamental foi orientada para que as práticas pedagógicas e a gestão das escolas se tornassem instrumentos ideológicos a serviço do enaltecimento de valores e atitudes tidos como alicerces de um patriotismo parametrizado por fatores genuinamente brasileiros, que deviam contrapor-se aos aspectos sociais e culturais estrangeiros (SANTOS, 2010, p. 108, grifos meus).

Como anteriormente indicado, a difusão de uma escola primária moderna, aos moldes republicanos, vinha sendo proposta através da criação dos grupos escolares. Essa empreitada, alicerçada por medidas lançadas a partir da década de 1910, tal como a reforma da Escola Normal Catarinense, tinha por objetivo a formação de professores modernos e patrióticos; nesse panorama, conforme as análises de alguns historiadores, o grupo escolar é visto "[...] como a escola da República por excelência [...] praticamente restrito ao mundo urbano $[\ldots]^{\prime \prime}$, sendo que nele também eram realizados rituais, especialmente as "festas escolares republicanas" de caráter cívico promotor do regime (TEIVE; DALLABRIDA, 201 1, p. 23 e 152). Devido a isso, faz-se necessário ter o grupo escolar como mais um parâmetro de análise e comparação, já que são tidos como emblemáticos da modernização educacional. Esse argumento vai ao encontro do que indica a pesquisa de Azevedo e Cabral (2015/2016, p. 177), dedicada às relações entre a República e as festas escolares num grupo escolar mineiro entre 1912 e 1930, segundo a qual as festividades "[...] representavam mais uma forma encontrada pelo diretor da 
escola para desenvolver, através de práticas "ritualizadas" e "simbólicas", os "ideais republicanos".

Conforme Teive e Dallabrida (2011), as festas e comemorações cívicas republicanas no Brasil - aqui entendidas como rituais - tiveram sua origem em legislação datada de 1890, sendo que, em Santa Catarina, foram reafirmadas, em 1914, como integrantes do Regimento Interno dos Grupos Escolares; a programação anual podia envolver atores da unidade escolar como o diretor, professores e alunos, mas também convidando familiares dos estudantes e autoridades externas das comunidades, devendo contemplar, no mínimo: o dia três de maio quando se homenageavam a Descoberta do Brasil e a Festa das Aves, o sete de setembro associado à Independência do Brasil e à Festa das Árvores, o 19 de novembro quando havia a Celebração da República e a Festa da Bandeira; por fim, a data de 30 de dezembro, onde se encerravam os trabalhos do ano letivo. Ademais, a pesquisa de Bencostta (2010) - sobre representações e imagens de festas escolares em grupos escolares de Curitiba - indica que, além daquelas reverenciando datas patrióticas, havia outras comemorações próprias da cultura festiva escolar:

[...] que a escola celebrava dentro de um calendário que, apesar de não ser tão rígido quanto o cívico, dispunha os alunos que, sob a supervisão dos seus professores, teatralizavam, em diferentes momentos do ano escolar, representações festivas de cunho religioso, popular e outros sugeridos pela própria escola (BENCOSTTA, 2010, p. 248).

Toma-se como premissa o fato de que as políticas educacionais que solicitavam a realização dos rituais atuaram desde as primeiras décadas do século XX e se perpetuaram durante os anos 1940, com idênticos objetivos formativos no conjunto das escolas primárias existentes. Mesmo que o Grupo Escolar fosse a instituição mais prestigiada do cenário educacional republicano, a exigência política de replicação dos rituais nas demais instituições de ensino primário, como nas escolas isoladas e desdobradas, seria também necessária, estabelecendo a irradiação e compartilhamento de mecanismos didático-pedagógicos de regulação e disciplinares, aos moldes de modernização nacional que se enfatizava. De modo geral, há concordância quanto à ritualização "[...] como um espaço de sociabilidade capaz de contribuir 
na construção de interpretações históricas do universo escolar" (BENCOSTTA, 2010 , p. 247).

Nesse âmbito, era preciso agir na internalidade dos trabalhos escolares, chegar às salas de aula e aos outros espaços - pátios, ruas, salões comunitários, entre outros -, agindo no ambiente social e orientando as comunidades quanto às mudanças. Para tanto, às práticas pedagógicas - como práticas sociais e históricas - acabaram sendo incorporados rituais formativos de cariz didático-pedagógico cívico e moralizador. Mas, na medida em que nas escolas das regiões de imigração alemã a realização de rituais se tornava prática recorrente, repetida e com ênfase nos conteúdos e atitudes que pudessem contribuir para a nacionalização, acabaria caracterizando um exercício de ritualismo.

\section{Um exame dos rituais: as cerimônias e festas escolares}

Desde os primórdios de sua instituição como prática curricular na escola primária catarinense, a realização de rituais era incumbência dos professores. Essa atribuição legal aos docentes fica clara num incisivo ofício de 16 de abril de 1923, assinado pelo Diretor da Instrução Pública Henrique Fontes e endereçado ao Secretário Municipal de Joinville Aristides Rego: "Confirmo meu telegrama de 14 do corrente, do teor seguinte: Professor João Welsch não poderá ser aproveitado porque foi exonerado por não querer participar festas cívicas realizadas por ocasião centenário independência. Saudações. Saúde e fraternidade" (SANTA CATARINA, 1923, grifo meu). Portanto, havia até mesmo punições pela não adesão às comemorações patrióticas.

Note-se que o professor citado tem sobrenome alemão e atuava na região de Joinville, uma importante área de colonização com imigrantes germânicos. Teriam sido esses os fatores culturais que o levaram a não querer participar das comemorações dos cem anos da independência do Brasil? Seria o professor Welsch orientado por uma racionalidade e percepção daquele ritual como algo externo e superficial, distante do simbolismo cultural que compartilhava? Fato é que o ambiente histórico republicano propunha uma ritualidade que preconizava expressar sua própria linguagem simbólica, presente desde as primeiras décadas do regime, como ratifica Araújo (2004, p. 135): "A década de 1920 foi pródiga em reverenciar símbolos nacionais 
(hinos, bandeiras, datas comemorativas, heróis, estátuas, obras e instituições), [...] como que garantidores de uma coesão social e de uma identidade dos indivíduos com a nação".

Conhecer e saudar os governantes integrava os conteúdos dos rituais. Para exemplificar, evidenciam-se comemorações referentes ao período de governo ditatorial de Getúlio Vargas. Da Escola Duque de Caxias, existe parte do Programa da inauguração dos retratos de Vargas e de seu interventor em Santa Catarina, Nereu Ramos, datado de novembro de 1941. Dividido em duas partes, na primeira indica o dia 10, que rememorava a implantação do Estado Novo, trazendo elementos do cenário político ao qual a escola e a comunidade estavam subordinadas:

\section{I. Às 9 horas concentração dos alunos e do povo. \\ II. Às 9 e 30 na sala de aula discurso da professora sobre o acon- tecimento sendo em seguida inaugurado o retrato do Chefe da Nação.$$
\text { [...] VIII - Hino Dr. Getúlio Vargas (IARAGUÁ DO SUL, 1941). }
$$

Note-se o protagonismo docente, a quem cabia conduzir o cerimonial. Em seguida, na parte cujo registro é de 15 de novembro, há uma proposta idêntica de organização do tempo: "I. Às 9 horas concentração dos alunos e do povo do pateo da escola. II. Às 9 e 30 reunião de todos [... na sala de aula onde usou a palavra a professora sendo em seguida inaugurado o retrato do Sr. Dr. Nereu Ramos" (JARAGUÁ DO SUL, 1941).

Uma fonte de 10 de novembro de 1941, da Escola Pública Municipal General Osório, descreve dois rituais de mesma natureza. $\bigcirc$ "Programa dos festejos realizados nesta escola em prol do Brasil Novo" mostra a penetração da proposta de formação cívica de abrasileiramento em regiões onde houve imigração europeia. Mantém o tom de enaltecimento dos líderes, próprio do autoritarismo, assim como enfatiza o território nacional como Minha terra, apelando ao repertório simbólico-cultural de pertencimento à nação, indicando não apenas o lugar onde se nasce, mas também onde se vive.

$2^{\circ}$.) Inauguração das fotografias de Dr. Getúlio Vargas e do Dr. Nerêu Ramos e preleção pela professora.

$3^{\circ}$.) Brasil Novo - canto.

$4^{\circ}$.) Minha terra - pela aluna Edite Becker. 
5\%.) Brasil - pelo aluno Evaldo Lierman.

$6^{\circ}$.) A juventude - pela aluna Arací Luneli UARAGUÁ DO SUL, 19411.

fato é que durante a campanha de nacionalização eram abundantes as exigências de ritualização envolvendo a população estudantil da escola primária, seja nos grandes atos públicos a que Vargas comparecia e que tinham lugar na capital federal ou em cidades maiores como São Paulo, seja nas iniciativas, construídas nas pequenas escolas interioranas e que buscavam reproduzir aquelas cerimônias conforme os recursos disponíveis. Tanto é que, em 1943, veio a público a obra Comemorações do Estado Nacional 19321942: na voz das classes e na palavra do chefe, destinada a historiar, em tom apologético, eventos acontecidos sob o comando de Vargas. Peça integrante do aparelho de propaganda montado no Estado Novo, a escrita apresenta a escola como lugar da infância e juventude. Numa das seções, traz "As homenagens do mundo infantil [...]", relatando celebração no Rio de Janeiro "[...] onde milhares de crianças das escolas públicas do Distrito Federal se reuniram para homenageá-lo, na manhã de 10 de novembro" (RIO DE JANEIRO, 1943, p. 45). $\bigcirc$ texto, marcado por tom épico, arrolando o cenário palaciano e a presença de uma multidão, fornecia exemplo de inspiração para o ritualismo que vinha sendo reproduzido, em menor escala, nas escolas catarinenses, sugerindo intensidade de exaltação dos presentes:

No momento em que o Presidente desceu do carro em frente ao edifício do Palácio Municipal, toda a massa infantil, em coro orfeônico, entoou o Hino Nacional, seguindo-se-lhes outros hinos e canções patrióticas que arrancaram aplausos prolongados da multidão estacionada nas imediações (RIO DE JANEIRO, 1943, p. 45).

Outro ritual, descrito no "Programa dos festejos nesta escola dia 15 de novembro" alude à Proclamação da República, mas, além disso, inclui itens de inspiração lúdica, como "Pirolito (bailado) pelos alunos", "O Batalhão (comédia) por um grupo de alunos" e "Carteei - pelo aluno Evaldo Lierman" UARAGUÁ DO SUL, 1941 1). Nesse caso, incorpora aspectos que visavam divertir e admite uma simbologia vinculada à cultura da infância, fácil de ser internalizada.

E foi num domingo, 29 de novembro de 1942, que ocorreu a Festa de Encerramento da Escola Isolada Municipal Duque de Caxias. $\bigcirc$ ritual consta 
de três partes, que envolveram os hinos Nacional e a Bandeira, mas também "As violetas (poesia)", "Jogos e brinquedos infantis e distribuição de prêmios" e "Exercício de Ginástica" (JARAGUÁ DO SUL, 1942). A Ginástica visava incutir obediência e respeito, numa perspectiva de militarização da infância própria da inspiração nacionalista. É evidente que, para dar suporte a tais práticas corporais, cuja função de disciplinar e controlar é latente, já existia, há algum tempo, literatura destinada à orientação docente. Os Exercicios de Gymnastica - Usados nas escolas publicas do Estado de Santa Catharina, por exemplo, reúnem instruções "Preliminares" como "O professor dará as vozes, tendo em vista que ellas sempre se compõem de dois tempos: o de advertencia e o de execução", "Exercicios preliminares para formatura" como "Direita - volver", "Descançar" e "Sentido", Formatura e Exercicios calistehnicos, sendo estes últimos destinados, também, às seções femininas (SANTA CATARINA, 1920). Essa componente do ritualismo corporal se espelhava nos ideais do escotismo então em voga. Portanto, vinha a se constituir também como expressão de características de base biológica, mas que se vincula à linguagem simbólica do ambiente cultural vivido e aos objetivos formativos almejados.

Portanto, a essa altura, é possível afirmar sobre a permanência his208 tórica das recomendações para que os rituais integrassem a rotina escolar. Segundo Azevedo e Cabral (2015-16, p. 181): "Existia uma fiscalização que visava avaliar as tarefas realizadas no estabelecimento, e se estas estavam de acordo com as disposições legais". O Diário Oficial do Estado, de 18 de dezembro de 1941, em que consta a Portaria n² 275 assinada por Ivo D’Aquino, Secretário de Estado nos Negócios do Interior e Justiça, não só confirma a presença de rituais como também indica formas para o seu controle ao serviço de inspeção escolar: no artigo $1^{\circ}$. exara que "Os processos ou papéis, relatórios, mapas, quadros, balancetes, atas, programas de festas, jornais escolares e, em geral, os documentos que, por si, contenham as informações necessárias não devem ser acompanhados de ofício [...]"; e no parágrafo $4^{\circ}$. recomenda aos inspetores que a "realização de festas e solenidades escolares" devia ser registrada no "[...] verso dos mapas de movimento" (SANTA CATARINA, 1941, p. 4, grifos meus).

Assim, regulada pela política educacional vigente, a inspeção escolar estava comprometida não somente com o registro de festas e solenidades, mas também com a nacionalização. De acordo com Santos (2008), os Termos de Visita dos inspetores às escolas catarinenses revelam um fundamento étnico 
distintivo. Por exemplo, o termo de 29 de outubro de 1941, assinado pelo inspetor João Romario Moreira, assim se refere ao alunado da Escola Municipal Desdobrada de Estrada Isabel Alto, no distrito de Hansa: "Alunos - mais ou menos desembaraçados e disciplinados; há 13 genuinamente brasileiros, 14 de origem italiana, 18 de origem polonesa e 41 alemã" "UARAGUÁ DO SUL, 1941). Cabe questionar o que o inspetor entendia por "genuinamente brasileiro", um ponto polêmico que alude ao fundamento racial da campanha de abrasileiramento e que impregna de significados o plano simbólico-cultural que envolvia as instituições e seus atores na década de 1940. Portanto, cabia ao inspetor escolar um registro particular: o de caracterizar a população infantil quanto à identidade étnica.

A maioria dos programas comemorativos foi manuscrita. Já o Convite e Programa de Homenagem ao Dia da Pátria é datilografado. Elaborado por alguém da Escola Isolada Municipal Osvaldo Cruz, município de Corupá, relata uma programação extensa, que começou com hasteamento e saudação à bandeira e com um "Discurso em homenagem à data pela Professora". Previa, em seguida, um "desfile até o salão" (um espaço comunitário) onde se realizou um "Programa Desportivo" com sete itens, entre os quais, uma "Demonstração de Educação Física". Por fim, uma "Parte Cívica no Salão" que incluía três momentos: no primeiro, envolvendo os hinos e a declamação; no segundo, trazendo quatro novas declamações poéticas como "Independência ou Morte" e "Viva D. Pedro"; e, na terceira parte, intitulada "Ato Variado", constam seis itens com títulos curiosos como Jujú Balangandans, Eu Dei (Canto) e Os Pretinhos da Guiné (ESCOLA ISOLADA MUNICIPAL OSVALDO CRUZ, [194?]). Acerca dessa última, pode-se inquirir sobre suas intencionalidades tendo em mente a terminologia pretinhos e a indicação de outro espaço geográfico que não o Brasil. Sair do ambiente escolar para abrigar boa parcela do diversificado programa evidencia que os objetivos de sua realização previam alcançar a comunidade externa, aumentando sua visibilidade. Quer dizer, criavam-se rituais a ser compartilhados pelo máximo de pessoas possível.

programa de encerramento das aulas de 1944 da Escola General Osório, datado de 30 de novembro, traz uma figura colorida que retrata uma menina de vestido azul, com laços de fita e que carrega um buquê. $\bigcirc$ programa era eclético:

\section{$1^{\circ}$.) Hasteamento da Bandeira com o Hino nacional.}


$2^{\circ}$.) Saudação pelo aluno Vanderlei Mauro Lenzi.

$3^{\circ}$.) Preleção pela professora.

$4^{\circ}$.) As férias - poesia - pela aluna Eri Gorisch.

$5^{\circ}$.) As aulas - poesia - pela aluna Darci Paulo.

$6^{\circ}$.) As férias - canto.

$7^{\circ}$.) Escola - poesia - pela aluna Rita Lenzi.

$8^{\circ}$.) O luar- canto.

$9^{\circ}$.) Caipira-comédia - por diversos alunos.

10'.) Encerramento com o canto do Hino Nacional.

A professora Sofia P. Lenzi (JARAGUÁ DO SUL, 1944).

Nota-se que os programas de encerramento do ano letivo, mesmo zelando pela formação cívica, por vezes admitiam maior leveza, incluindo números em que os alunos podiam expressar linguagens como a teatral. Isso o que está previsto na comédia cujo nome alude a um personagem típico do ambiente rural brasileiro. A professora Sofia tanto registra sua participação na cronologia de atos como assina o programa.

Durante o ano, os rituais patrióticos eram indefectíveis. $\bigcirc$ programa de

2107 de setembro da Escola Mixta Municipal Duque de Caxias, em sua primeira parte, inclui: os hinos Nacional, da Independência e à Bandeira, marcha e desfile, os títulos "O grito do lpiranga" e "Auri-verde Pendão"; depois cita uma "Tarde desportiva" (UARAGUÁ DO SUL, 1945). Da mesma escola, fonte de 28 de novembro de 1945, se refere aos ritos de encerramento e traz uma observação peculiar no item 9: "Preleção da professora em homenagem de nosso Estado e seu digno Govêrno que emprega todos os meios possíveis para a alfabetização de seus filhos". Esse documento indica, sob tom apologético, o quanto o grupo docente estava alinhado às propostas da legislação educacional. Atendendo aos propósitos de ultrapassar os muros da escola nas demonstrações de civismo, a programação incluía, na segunda parte, item 2 "Às 10 horas - Desfile pela rua e canções patrióticas" (JARAGUÁ DO SUL, 1945).

A ênfase na liberdade da nação era um dos tópicos mais recorrentes no currículo ritualizado. Sob tal ideário, na Escola Isolada Pública Municipal Luis Delfino, confeccionou-se a Ata de 7 de setembro de 1944, aludindo à Independência do Brasil. Está em destaque o uso do termo colonos, que, nesse caso, revela a localização da instituição em ambiente rural e o fato de o ritual ser compartilhado não somente pelo alunado. Era importante que a comunidade 
se envolvesse nas atividades cívico-patrióticas. O fato de serem citados os colonos indica a população constituída por descendentes de imigrantes.

[...] tendo comparecido os alunos de ambos os sexos, em número de 29 alunos matriculados nessa escola. Às 8 horas da manhã deu-se início a festa, o Hasteamento da Bandeira ao som do Hino Nacional poesias recitativas e cantos pelos alunos. Lavrei a presente ata, que vai assinada pelos presentes e por mim. Tendo comparecido alguns colonos (CORUPÁ, 1944, grifo meu).

Nessa programação, constam 18 itens, sendo o último deles "Meu Brasil por 8 alunos. Hino Getulio Vargas pelos alunos". No final, havia "jogos lícitos" como "corrida da agulha, corrida de saco, corrida dos ovos, a cadeira e o bombom, jogo do galo, o carrinho humano, o anel, o lápis, etc" (CORUPÁ, 1944). Essa miscelânea de atividades compondo os rituais demonstra um cuidado no seu planejamento, com uma ordenação do tempo compartilhada entre a parte patriótica e a lúdica. Se esse ritual comportava momentos divertidos, estima-se que, para alguns dos professores, uma programação apoiada na exclusiva sucessão de atos cívicos deixaria a celebração monótona e cansativa para as crianças. Cabia mesclar o programa com ludicidade e atividades prazerosas próprias do universo infantil.

Pode-se imaginar o comportamento exigido das crianças durante tais rituais, fossem eles numa escolinha isolada ou na presença do Presidente. Tem-se um exemplo emblemático do texto de Comemorações do Estado Nacional, que deu voz à criança brasileira representada por Miriam, encarregada num ato solene de saudar Vargas:

PALAVRAS DE IMPROVISO PELA MENINA MIRIAM JOPPERT DE MOURA

Sr. Presidente:

Em nome de todas as crianças, venho, para bem de todas nós e do Brasil, desejar a v. excia. muitas felicidades e muita saúde.

Todas as crianças do Brasil gostam muito de v. excia. E sabem que v. excia. também thes quer muito bem e nelas muito confia. Vemos sempre a fotografia de v. excia sorrindo entre as crianças e assim the desejamos sinceramente todas as felicidades que serão também a nossa felicidade (RIO DE JANEIRO, 1943, p. 47). 
Questiona-se o quanto havia de improviso na fala atribuída à menina. E sobre o conteúdo, procura sublinhar uma relação afetuosa entre o Presidente e as crianças, que seria benéfica para ambas as partes. Outrossim, a fotografia de Vargas "sorrindo entre as crianças" estabelece ilações entre o teor do ritual e o significado social que dele é desejado.

Refere-se aquela mesma escola, datada de 30 de novembro de 1944, a Ata da festa de encerramento. Contém 14 itens indicando civismo, além de um fundo étnico apontado em títulos como "Sul Americano" e "A baiana". Além disso, nessa fonte, aparece um matiz religioso no título "Virgem do Amparo" (JARAGUÁ DO SUL, 1944). Entende-se que a presença de tal elemento pode servir para reforçar uma interação entre as componentes formativas escolares e o mundo religioso, numa superposição de finalidades. Mesmo admitindo um caráter institucional laico para a escola, assim como para as orientações de inspiração nacionalista, vale lembrar que rituais (e ritos) religiosos são igualmente utilizados na formação infantil.

Analisa-se ainda o documento de 26 de novembro de 1944, também referente a um encerramento de ano letivo. Redigido pelo professor Manoel Luiz Silva, descreve a cerimônia na Escola Osvaldo Cruz, composta por duas 212 partes; a "Parte cívica" e o "Ato variado". Na Parte cívica, que arrola os hinos, canções e poesias, aparece um item diferente, mas próprio da ritualística, conferindo formalidade: "4 - Entrega dos 'certificados de conclusão do curso",; já na outra parte, foi previsto o número "3 - $\bigcirc$ médico doente (comédia)", o que mostra a variedade de proposições didáticas em uso, que envolviam o canto e a poesia (CORUPÁ, 1944). De acordo com Bencostta (2010, p. 263), a festa de encerramento do ano letivo também era realizada nos grupos escolares, mas sua organização, na escola primária, passou a incluir a ritualização própria das formaturas e colações de grau típicas dos outros níveis de ensino: "A celebração também assume contornos de formatura e aquisição de graus semelhantes aos rituais do ensino secundário e superior [...]".

Os conflitos gerados pela exigência de uso do vernáculo num cenário em que nos primórdios prevalecia o idioma alemão ficam evidentes quando se observa o programa da Escola Lauro Müller, de novembro de 1945, do qual foi extraída a redação em que se notam diversos erros: "O enceramento do fim das aulas, desta escola se deu no dia 28 de novembro de 1945. E nós tivéramos como enceramento, os seguintes números" (CORUPÁ, 1945, grifos meus). Ainda que a escrita tenha sido de autoria de um professor ou de um aluno, 
indica pouco domínio da língua portuguesa. Portanto, reforçaria a necessidade de ainda mais abrasileirar, de fazer penetrar a componente idiomática própria da nação.

Neste sentido, há fontes que evidenciam o ritualismo mantido por organizações do trabalho intraescolar como a Liga Pró-Língua Nacional, criada sob a campanha de nacionalização para contemplar a questão linguística, um dos problemas na escolarização das crianças descendentes de imigrantes. Segundo um Relatório das atividades das principais associações, anexa a esta escola, de novembro de 1946, uma série de rituais de distinção envolviam a Liga Pró-Lingua Nacional, comprometendo as próprias crianças com a missão de corrigir os colegas quanto à pronúncia da língua portuguesa. Conforme a professora Lilia Ayroso:

No princípio deste ano foi eleita a nova diretoria e adquirido um livro especial para o registro dos atos mais importantes desta associação. Os membros da diretoria passaram a usar no braço esquerdo um distintivo, uma fita verde e amarela bordada, de $5 \mathrm{x}$ $3 \mathrm{~cm}$. Todos os sábados é enfeitado com flores naturais dois vasos que estão colocados ao pé do mastro onde se hastea a Bandeira Brasileira. Os alunos que compõe a diretoria se encarregaram com perseverança e entusiasmo, corrigindo os principaes defeitos de pronúncia da nossa bela língua vernácula, tais como: tera, sera, guera, pincha, etc, dando ótimo resultado esta providencia, que foi tratada com fé pela grandeza do Brasil (sic) UARAGUÁ DO SUL, 1946, grifo meu).

Vê-se a intenção de combater a fala própria de parte da população escolar - que, provavelmente, era descendente de imigrantes - destacando-se as palavras com dois erres e cuja pronúncia também deveria atender à questão fonética associada; porém, para as crianças falantes do alemão como primeira língua, acabavam sendo escritas e pronunciadas como se tivessem um erre apenas, o que era aprendido desde o ambiente familiar.

Acrescentam-se algumas fontes cuja datação é posterior ao fim do Estado Novo, mas que evidenciam a continuidade da finalidade formativa dos rituais na última metade da década de 1940. Veja-se que, naquela mesma escola, aconteceu a programação da Festa do Dia 7 de setembro de 1946. Fala de início previsto para as oito horas e finaliza com o item "arriamento a bandeira nacional" às 18 horas. Como de praxe, a primeira parte arrola os 
hinos e poesias; a segunda, "Às 15 horas, brinquedos jogos e prêmios para todos os alunos" (UARAGUÁ DO SUL, 1946). Ainda se aliavam componentes do ritualismo cívico a itens mais leves e apropriados para o público infantil, com premiação para todos. Isso que poderia reforçar a adesão ao cerimonialismo.

Por sua vez, o Programa da festa do dia 7 de setembro da Escola Municipal Mista Desdobrada Machado de Assis, de 1946, apresenta os habituais rituais, mas traz uma diferenciação quanto à parte lúdica, ainda não externalizada em outras fontes: "Jogos para - Rapazes Jogos para - Meninas" (JARAGUÁ DO SUL, 1946). Isso significa que, embora a escola fosse mista, ainda permanecia a distinção de gênero quanto ao tipo de atividade a ser realizada. Mas, nesse período, já havia escolas onde uma mesma classe era frequentada por crianças de ambos os sexos, embora posicionadas em fileiras distintas. Seções femininas, completamente separadas das masculinas, ocupando salas diferentes, não eram mais usuais.

Em programação de 7 de setembro de 1946 aparecem itens não encontrados em outras cerimônias, como "Papai partiu para a guerra", "Eu sou catarinense" e outros que sugerem a moralização da infância como "A mentira" e "A menina desobediente" (JARAGUÁ DO SUL, 1946). Portanto, algumas das

214 componentes, propostas pelos títulos dos rituais, põem em destaque uma essência formativa que defendia certos princípios da moral, assim como referentes a atitudes cívicas e de devoção à pátria, como lutar numa guerra. O Programa da festa do encerramento da Escola Municipal Darci Vargas, de novembro de 1947, inclui poesias como "A bandeira", "O marinheiro", "Nosso Brasil", "O gato vaidoso", "Os cinco dedos da mão", "O 'pão-duro'", "O estudante" e "Uma carta", permeadas pelos hinos (JARAGUÁ DO SUL, 1947).

Já o documento de quatro de setembro de 1947, da Escola Lauro Müller, aborda o dia da Pátria: pela manhã, com os hinos e poesias; à tarde, com esportes, Hino Nacional, Juramento à Bandeira, Hino da Independência e "Marcha Militar" (CORUPÁ, 1947). A presença dos hinos e da marcha militar aponta para a manutenção do objetivo de que os rituais continuassem a promover sentimentos de afeição à nação brasileira. $\bigcirc$ juramento à bandeira ressaltaria o simbolismo de fidelidade ao país.

As cerimônias podiam ser complexas em sua estrutura, conjugando várias atividades. Vale destacar o "Programa da festa escolar a realizar-se nesta escola no dia 21 do corrente", documento de agosto de 1949 e que 
noticiava o evento da Escola Estadual Desdobrada Mista de Barra do Ribeirão Grande do Norte. Note-se que, embora datada de fins da década de 1940, pós-Estado Novo getulista, trata-se de uma programação de cunho didático-pedagógico, mas que envolve também aspectos da gestão política mais ampla e da religiosidade, indicando a permanência do ritualismo. A redação é bem cuidada, talvez construída por um adulto, com o emprego de termos que sugerem a origem escolar da escrita:

$1^{a}$. parte:

Às 9 horas - Inauguração pelo Exmo. Sr. Prefeito Municipal do novo prédio da escola e entronização na sala de aula da imagem de Jesus Crucificado.

Às 9,30 horas - Missa solene e campal em ação de graças pelo restabelecimento da saúde do preclaro Governador do Estado Dr. Aderbal Ramos da Silva.

$2^{a}$. parte:

Das 11 às 13 horas - Os alunos da escola desenvolverão seleto programa de cantos, recitativos e diálogos escolares.

$3^{a}$. parte:

Às 13 horas - Encontro amistoso de futeból entre os principais esquadrões do Sport Club Paraná local e do valoroso Independiente da cidade de Jaraguá.

Às 15 horas - Jogo amistoso entre as equipes do Estrela Footbal Club de Nereu Ramos e do D. Pedro Il de Corupá.

Haverá churrascada, café, doces, bebidas, tiro ao alvo etc. Abrilhantará a festa o famoso Jazz Gadotti.

Convidam-se as Autoridades e o Povo em Geral UARAGUÁ DO SUL, 1949, grifos meus).

Aspectos peculiares estão presentes na primeira parte. Inicialmente, a mescla entre aspectos do universo laico que é pontuado pela inauguração do novo prédio com o fator religioso dado pela entronização da imagem sacra na sala de aula. A seu lado, a realização de uma missa pela saúde do governador do estado. A programação evidencia ainda as relações entre a comunidade e a escola, trazendo elementos étnicos, como indica o tiro ao alvo - prática introduzida pelos colonizadores alemães e o futebol, este considerado mais brasileiro. A extensão do convite a autoridades e à população em geral mostra a percepção de que as interações entre a instituição educativa e o entorno 
podem concorrer para que objetivos comuns sejam atingidos. Como se ratifica, as festas escolares são "[...] produções do seu cotidiano, com uma ação, um tempo e um lugar determinado, o que resulta na concentração de afetos e emoções em torno de um assunto que é celebrado e comemorado, cujo principal produto é a simbolização da unidade dos participantes" (BENCOSTTA, 2010, p. 248).

Na Escola Lauro Müller, houve, em cinco de novembro de 1949 "Homenagem ao Centenário Rui Barbosa", dedicada ao político e intelectual, misturando hinos e poesias. A parte dedicada a Rui Barbosa ficou a encargo da mestra: "1 1 ${ }^{\circ}$. - Preleções: sobre a data, pela Professora" (CORUPÁ, 1949).

Uma das datas mais festejadas era a Independência. Assim, a Homenagem ao Dia da Pátria, de sete de setembro de 1949, na Escola Mista Municipal Orestes Guimarães, tinha um Ato Cívico, com os habituais hinos e poesias e um Ato Variado "1․ Exercícios ao ar livre, tais como: corridas e outras manobras; $2^{\circ}$. Distribuição de prêmios, balas, doces, etc" UARAGUÁ DO SUL, 1949). A leveza do denominado Ato Variado remete a interpretações sobre a presença dos rituais como elemento da cultura escolar infantil naquele contexto.

Da mesma escola, há o Programa de encerramento da Semana da Criança, de sete de outubro de 1949, constando de duas partes. Da primeira, destacam-se dois itens: "4․ Preleção sobre a "Semana da Criança" pelo professor, apelando para a sua colaboração nesse sentido [...] $6^{\circ}$. A criança brasileira e a sua atual proteção esplicado por um aluno do terceiro ano"; já, noutra, vê-se que os rituais se prestaram também como cenário para atuação da administração local, que aproveitou a oportunidade para "Distribuição de cadernos, fornecidos especialmente pela Prefeitura Municipal" "UARAGUÁ DO SUL, 1949). Sobre a celebração do dia da criança, Bencostta (2010, p. 257258) afirma que foi instituída pelo Decreto-Lei no. 4.867, de 5 de novembro de 1924, que determinou o dia 12 de outubro para a comemoração anual; em Curitiba, todavia, há registros dos primeiros festejos concernentes à efeméride a partir de 1927, sendo que, nas primeiras edições, o ritual tinha um caráter cívico pronunciado aliado a uma demonstração de conhecimento sobre conteúdos escolares; mas com o passar do tempo "[...] as programações assumiram configurações mais atraentes para as próprias crianças, apesar da insistência do formato organizacional da mente adulta pra a festa." 
Remetendo ao cenário catarinense, tem-se a "Homenagem ao Dia: Semana da Criança", de 18 de outubro de 1950, assinada pela professora Emma Scheibel. No alto, consta "A Criança de hoje é o Brasil de Amanhã"; no final da página, encontra-se outro lema: "Tudo pela Grandeza do Brasil" (JARAGUÁ DO SUL, 1950). Nota-se que, mesmo finda a ditadura de Vargas e adentrado os anos 1950, ainda persistem os indicativos de nacionalização, presentes nos rituais escolares (SANTOS, 2008a).

A "Homenagem do dia 15 de novembro de 1950", na Escola Mista Municipal Princesa Isabel de Pedra d'Amolar Alto, envolveu 24 itens, sendo o último dedicado a várias canções que foram apresentadas individualmente por algum aluno ou entoadas por todos, com títulos como Mocidade, Canção do Soldado, Hino ao Brasil, Canção do Marinheiro, Sítio de Caboclo e Hino da Despedida (JARAGUÁ DO SUL, 1950). Questiona-se o que tais canções poderiam significar na relação com o cotidiano das crianças. Que sentido tem uma Canção do Marinheiro numa região rural, distante do litoral e onde os habitantes provavelmente jamais tinham visto o mar? Serviria talvez para um fim militarizante, mostrando uma modelagem representada pelos marinheiros e soldados que estão a serviço da pátria, cumprindo uma missão esperada da mocidade brasileira.

\section{Considerações finais}

Constata-se que os rituais têm origem legalmente instituída nos primórdios da República e permanecem como recorrente componente formativa da infância pelas décadas seguintes. Ou seja, os resultados indicam que eles serviram à formação da infância no período republicano em apreço, sendo que se encontram comemorações e festividades ritualísticas nas escolas primárias catarinenses ao longo da década de 1940.

A análise do teor das atas e programas de cerimônias realizadas nos tipos de instituições primárias que foram alvo desta pesquisa - escolas municipais isoladas, desdobradas mistas e estadual desdobrada mista, desvelou seu caráter ritualista, tal como demonstrado por Teive e Dallabrida (201 1) e Bencostta (2010) ao estudarem os rituais nos grupos escolares. Os resultados confirmam a hipótese de que a realização de festas escolares foi protagonizada pela diversidade de instituições educativas do ensino primário, 
igualmente responsabilizadas desde os primórdios do século XX pela difusão de valores, deveres e hábitos que estivessem em sintonia com os preceitos republicanos (AZEVEDO; CABRAL, 2015/2016). No caso das escolas primárias catarinenses situadas em áreas rurais de colonização com imigrantes alemães, acrescentava-se à ritualidade uma significativa ênfase em ingredientes de nacionalização.

E os professores foram incumbidos de organizar e levar a efeito práticas que pudessem dar conta dessa espécie de compromisso com a nação brasileira. Aos inspetores escolares cabia fiscalizar o registro da realização de rituais. Várias das fontes, além de apresentarem o rol das práticas integrantes dos rituais, foram ilustradas com elementos simbólicos que auxiliam nas representações que exprimem nacionalismo, tais como as cores nacionais, bandeiras e brasões, embora ocorram ilustrações próprias de uma cultura da infância. Em certos casos, apresentam erros na redação.

Alguns documentos citam discursos dos professores como integrantes das comemorações e homenagens. Contudo, a maior parte da cerimônia envolvia atividades de recitar, cantar e interpretar a serem realizadas pelas crianças, aludindo a datas cívicas como 7 de setembro e Proclamação da 218 República. Como reafirmam Azevedo e Cabral (2015/2016, p. 175): "[...] podemos perceber que as datas da Independência do Brasil e da Proclamação da República sempre eram muito comemoradas". Ou homenageavam-se personalidades como Rui Barbosa. Muito se festejou o presidente Getulio Vargas, sobretudo durante o Estado Novo.

Por vezes, configurou um ritual extenso, dividido em partes e ocupando um dia inteiro. Entoavam-se não apenas os hinos oficiais, mas também aqueles dedicados a vultos históricos e canções cívicas que exaltavam o Brasil Novo e a postura que se desejava das crianças, os futuros cidadãos. Os alunos recitavam poemas de inspiração nacionalista como $\bigcirc$ Brasil, Saudação à Bandeira, A Independência, Defendamos o Brasil, Pátria Sacrossanta, Minha Terra, Grande Pátria; em alguns deles se vê um caráter regional: Eu sou catarinense. Vários poemas tratavam de questões morais ou religiosas, imprescindíveis à formação.

Os rituais também marcavam a Semana da Criança e o encerramento do ano. Em certos momentos, as festas escolares podiam se destinar a prover fundos e incluíam venda de bebidas, assados e café com doces. Podiam 
abrigar atividades como futebol, tiro ao alvo e grupos musicais que animavam a celebração - estas duas últimas características da cultura alemã que resistia no cenário. Há programas incluindo atividades teatrais, além de jogos e brinquedos, embora fique evidente certa sisudez nas solenidades, em boa parte isentas de elementos lúdicos que tornariam mais agradáveis os rituais, aproximando-os do universo da infância. Mas alguns programas citam a distribuição de prêmios, doces e balas - aspecto que pode ser alinhado ao mundo infantil. Aparecem demonstrações de Educação Física, de ginástica ou exercícios ao ar livre, tudo utilizado com propósitos formativos.

Ficou evidente a centralidade da questão linguística nos processos de nacionalização sintonizados com o funcionamento da escola primária em Santa Catarina, e que, em maior ou menor grau, tinham lugar nos rituais. Comprova tal aspecto a referência às Ligas Pró-Língua Nacional, que combatiam os problemas gerados pelo bilinguismo da população infantil. Eram necessárias correções textuais e também da pronúncia do vernáculo, o que se buscava fazer através dos cantos e do recitar inclusos nas cerimônias.

Participavam das cerimônias os alunos capitaneados pelos seus professores, mas também autoridades e a comunidade, notadamente os pais. Estas aconteciam nas instalações da escola, mas também podiam ir além dos muros: envolviam-se as crianças em passeatas, marchas e desfiles nos arredores - entendidos como tendência de militarização, também atribuída à educação física e incorporada às escolas primárias quando se tomou o escotismo e o serviço militar como padrões.

Os rituais compunham na introdução de um novo ritmo ao calendário escolar, tendo como objetivo regrar e regular. Na construção de um Estado moderno e de uma nação homogênea - um dos escopos do governo brasileiro à época -, a ocupação do tempo poderia ser aprendida na escola, para ser sintonizada com a organização da vida cotidiana pautada pelo urbano e pela indústria, que distanciava dos modos de referência rurais. A integração aos padrões urbanos exige respeitar, principalmente, a temporalidade ditada pelo Estado.

A variedade de itens evidencia um fundo moralizante de acordo com o nacionalismo. Sublinha o ritualismo e seus objetivos formativos político-pedagógicos durante a década de 1940, momento de conformação da escola primária de Santa Catarina ao ideário nacionalista do regime de 
governo de Vargas, sobretudo no autoritário período do Estado Novo (19371945) (SANTOS, $2010 ;$ 2009; PANDOLFI, 1999; MÜLLER, 1994). Analisado o conjunto documental, ficou evidente seu cariz ritualista. As atas e programas das cerimônias e festas escolares delineavam uma finalidade: contribuir para a nacionalização da população infantil em meio cultural com presença de aspectos estrangeiros, utilizando-se, repetidamente, os rituais num projeto de abrasileiramento e atendimento ao contexto político de governo.

A pesquisa confirmou perspectivas historiográficas que identificaram as prerrogativas da campanha de nacionalização da era Vargas noutras fontes documentais ligadas à escola, tais como: livros didáticos, cadernos escolares, fotografias e termos de visita de inspeção, bem como na literatura da época que serviu de propaganda para o regime de governo em seus propósitos de nacionalização (GUASTINI, 1943; BETHLEM, 1939). O ritualismo, como afirma Santos (2010), pode ser incluído no currículo efetivado com propósitos de abrasileiramento, mostrando que há uma natureza peculiar nas propostas curriculares previstas pela legislação da época, particularmente para as instituições escolares dos núcleos de colonização alemã.

À medida que solicita uma série de ações levadas a efeito nas insti220 tuições escolares, o ritual tem um alto valor simbólico. Ao expressar crenças, buscar despertar emoções e conformar identidades, o ritualismo pode ser usado como estratégia para a introdução e manutenção de relações sociais que se deseja construir, ao mesmo tempo que pretende gerar uma desejada integração dos indivíduos nos contextos mais amplos, embora escamoteando o seu real e intrínseco significado. Na instituição educativa, a constante repetição dos rituais almeja conseguir, por meio da impregnação dos símbolos do campo cultural dominante, a adaptação dos atores escolares a uma realidade apresentada como organizada e desejável.

\section{Referências}

ARAÚjO, Marta Maria. A educação tradicional e a educação nova no Manifesto dos pioneiros (1932). In: XAVIER, Maria do Carmo (Org.). Manifesto dos pioneiros da educação: um legado educacional em debate. Rio de Janeiro: Editora FGV, 2004.

AZEVEDO, Denilson Santos de; CABRAL, Talitha Estevam Moreira. A criação do Grupo Escolar Silveira Brum e seus primeiros anos de funcionamento: relações entre a república e 
as festas escolares (1912-1930). Educação em Foco, Juiz de Fora, v. 20, n. 3, p. 165-186, nov. $2015 / \mathrm{fev} .2016$.

BARDIN, Laurence. Análise de Conteúdo. Lisboa: Edições 70, 1977.

BENCOSTTA, Marcus Levy Albino. História da educação e cultura escolar: representações e imagens das festas escolares. In: VIDAL, Diana Gonçalves; SCHWARTZ, Cleonara Maria (Org.). História das culturas escolares no Brasil. Vitória: EDUFES, 2010.

BETHLEM, Hugo. Vale do Itajaí: jornadas de civismo. Rio de Janeiro: Livraria José Olympio Editora, 1939.

BOMENY, Helena Maria Bousquet. Três decretos e um ministério: a propósito da educação no Estado Novo. In: PANDOLFI, Dulce (Org.). Repensando o Estado Novo. Rio de Janeiro: Fundação Getúlio Vargas, 1999.

CORUPÁ. Escola Isolada Municipal Osvaldo Cruz. Convite e Programa de Homenagem ao Dia da Pátria. Corupá, [194?] (datilografado).

. Escola Isolada Municipal Osvaldo Cruz. Encerramento do ano letivo. Corupá, 30 nov. 1944 (manuscrito).

. Escola Isolada Pública Municipal Luis Delfino. Ata de encerramento do ano letivo. Corupá, 30 nov. 1944 (manuscrito).

Escola Isolada Pública Municipal Luis Delfino. Ata de 7 de setembro de 1944. Corupá, 7 set. 1944 (manuscrito).

Escola Mista Municipal Lauro Müller. Homenagem ao dia: semana da criança. Corupá, 18 out. 1950 (manuscrito).

. Escola Mista Municipal Lauro Müller. Homenagem ao dia da Pátria. Corupá, 5 set. 1947 (manuscrito).

. Escola Mista Municipal Lauro Müller. Programa de encerramento. Corupá, 28 nov. 1945 (manuscrito).

Escola Mista Municipal Lauro Müller. Homenagem a Centenário Rui Barbosa. Corupá, 5 nov. 1950 (manuscrito).

. Escola Mista Municipal Princesa Isabel de Pedra D'amolar Alto. Homenagem do dia 15 de novembro de 1950. Corupá, 15 nov. 1950 (manuscrito).

CURY, Carlos Roberto Jamil. Educação e contradição. São Paulo: Cortez, Autores Associados, 1987. 
FIORI, Neide Almeida (Org.). Ełnia e educação: a escola "alemã" do Brasil e estudos congêneres. Florianópolis: Editora da UFSC; Tubarão: Editora Unisul, 2003.

FLORIANÓPOLIS. Diretoria de Instrução Pública. Ofícios. Florianópolis, 16 abr. 1923. (impresso).

GUASTINI, Raul. Ideário político de Getulio Vargas. São Paulo: Revista dos Tribunais, 1943. JARAGUÁ DO SUL. Escola Mixta Municipal Duque de Caxias. Programa de inauguração dos retratos dos Exmos. Srs. Dr. Getúlio Vargas e Dr. Nereu Ramos. Jaraguá do Sul, 10 nov. 1941 (manuscrito).

Escola Municipal Desdobrada General Osório. Programa dos festejos realizados nesta escola em prol do Brasil Novo. Jaraguá do Sul, 10 nov. 1941 (manuscrito).

Escola Municipal Desdobrada General Osório. Programa dos festejos nesta escola dia 15 de novembro. Jaraguá do Sul, 15 nov. 1941 (manuscrito).

Escola Municipal Desdobrada General Osório. Programa dos festejos realizados nesta escola no encerramento das aulas. Jaraguá do Sul, 30 nov. 1941 (manuscrito).

Escola Mixta Municipal Duque de Caxias. Festa de Encerramento. Jaraguá do Sul, 29 nov. 1942 (manuscrito).

222 . Escola Municipal Desdobrada General Osório. Programa de encerramento das aulas de 1944. Jaraguá do Sul, 30 nov. 1944 (manuscrito).

Escola Mixta Municipal Duque de Caxias. Programa de 7 de setembro. Jaraguá do Sul, 4 set. 1945 (manuscrito).

Escola Mixta Municipal Duque de Caxias. Encerramento do ano letivo. Jaraguá do Sul, 28 nov. 1945 (manuscrito).

Escola Mista Municipal Darci Vargas. Programação de 7 de setembro. 1946. Jaraguá do Sul, 5 set. 1946 (manuscrito).

Escola Municipal Mista Desdobrada Machado de Assis. Programa da festa do dia 7 de setembro. Jaraguá do Sul, 8 set. 1946 (manuscrito).

Escola Mista Municipal Orestes Guimarães. Programa da festa de encerramento. Jaraguá do Sul, 28 nov. 1946 (manuscrito).

Escola Mista Municipal Orestes Guimarães. Relatório das atividades das principais associações, anexa a esta escola. Jaraguá do Sul, 30 nov. 1946 (manuscrito).

Escola Mista Municipal Darci Vargas. Programa da festa do encerramento. Jaraguá do Sul, 30 nov. 1947 (manuscrito). 
Escola Estadual Desdobrada Mista de Barra do Ribeirão Grande do Norte. Programa da festa escolar a realizar-se nesta escola no dia 21 do corrente. Jaraguá do Sul, 21 ago. 1949 (manuscrito).

. Escola Mista Municipal Orestes Guimarães. Homenagem ao Dia da Pátria. Jaraguá do Sul, 7 set. 1949 (manuscrito).

. Escola Municipal Desdobrada General Osório. Programa dos festejos realizados nesta escola em prol de 7 de setembro. Jaraguá do Sul, 7 set. 1949 (manuscrito).

MÜlLER, Telmo Lauro (Org.). Nacionalização e imigração alemã. São Leopoldo: Editora Unisinos, 1994.

NAGLE, Jorge. A educação na Primeira República. In: HOLLANDA, Sérgio Buarque de. História geral da civilização brasileira. 4. Ed. 1997. (Tomo III, v. 2, livro 3\%).

PANDOLFI, Dulce (Org.). Repensando o Estado Novo. Rio de Janeiro: Editora Fundação Getúlio Vargas, 1999.

RIO DE JANEIRO. Comemorações do Estado Nacional 1932-1942: na voz das classes e na palavra do chefe. Rio de Janeiro, [s.n.], 1943 (impresso).

SANTA CATARINA. (Estado). Portaria n. 275, de 17 de dezembro de 1941. Simplificação e sistematização de expediente das Inspetorias Escolares e Estabelecimentos de Ensino. Diário Oficial [do] Estado. Florianópolis, 18 dez. 1941, p. 2161.

SANTA CATARINA. Os exercicios de gymnastica - usados nas escolas publicas do Estado de Santa Catharina. Blumenau: Lito e Typographia Hömke Irmãos, 1920.

SANTOS, Ademir Valdir dos. A inspeção escolar e a campanha nacionalista: políticas e práticas na escola primária catarinense. Revista Educação em Questão, Natal, v. 33, n. 19, p. 229-252, set./dez. 2008.

Estado Novo, o período pós 1945 e as escolas primárias catarinenses: (des) nacionalização do ensino estrangeiro? Revista HISTEDBR, Campinas, n. 32, p. 65-84, 2008a.

A política educacional nacionalista e o aspecto linguístico: vestígios na escola primária. Revista Brasileira de Estudos Pedagógicos, Brasília, v. 90, n. 225, p. 51 1-527, maio/ago. 2009

Educação e nacionalismo: configurando a escola primária catarinense na Era Vargas. Revista Brasileira de História da Educação, Campinas, n. 24, p.83-1 1 1, set./dez. 2010 . 
Zeitgeist ou espírito alemão: etno-história de germanidade e instituição da escola em Santa Catarina. Educação e Pesquisa, São Paulo, v. 41 , n. 2, p. 325-340 abr./jun. 2015. As escolas alemãs em Santa Catarina e sua transformação para teuto-brasileiras: uma análise histórica. Acta Scientiarum. Education, Maringá, v. 36, n. 2, p. 233-242, july/ dec. 2014.

TEIVE, Gladys Mary Ghizoni; DALLABRIDA, Norberto. A Escola da República: os grupos escolares e a modernização do ensino primário em Santa Catarina (191 1-1918). Campinas: Mercado de Letras, 2011.

Prof. Dr. Ademir Valdir dos Santos Universidade Federal de Santa Catarina Departamento de Estudos Especializados em Educação Programa de Pós-Graduação em Educação Líder do Grupo de Estudos e Pesquisas em História da Educação e Instituições Escolares de Santa Catarina (GEPHIESC/UFSC/CNPq) E-mail: ademir.santos@ufsc.br 